\section{The importance of evaluation and evidence- based skills to improving service delivery}

\author{
Sarah McNicol
}

\begin{abstract}
Author
Sarah McNicol is a researcher at evidence base research and evaluation at the University of Central England. She has worked on a variety of research and evaluation projects including projects intended to support and develop evaluation skills including the evalued project which focuses on the evaluation of electronic services in HE libraries and the development of a self-evaluation scheme for school libraries.

Email: Sarah.McNicol@uce.ac.uk
\end{abstract}

\begin{abstract}
The overall aim of the MLA-WM funded Developing Evaluation and Evidence-based Skills and Approaches to Service Delivery project is to improve the evaluation skills of staff within the museums, libraries and archives sectors and the focus of the project will be on evaluation of service provision. The partners in this project include museums, academic libraries and their archives, public libraries and their archives and health libraries. The first stage of the project, which is reported here, was to carry out an investigation of needs in terms of staff skills, focusing on evaluation, within the sector. The findings of this investigation will be used to inform the development of an approach to training which will be delivered in early 2006. The findings suggest that museums, archives and libraries need to streamline existing data collection exercises; dramatically improver the organisation and management of evaluation activities; and make stronger links between evaluation and service development.
\end{abstract}

\section{Acknowledgement}

This research was funded by the MLA-WM (The Council for Museums, Archives and Libraries - West Midlands).

\section{Introduction}

The Developing Evaluation and Evidence-based Skills and Approaches to Service Delivery project funded by the MLA-WM will develop the museums, libraries and archives workforce in the West Midlands in terms of evaluation skills which will, in turn, promote service development. Through evaluation, organisations can plan, reflect, learn and improve. The overall aim of the project is to improve the evaluation skills of staff within the museums, libraries and archives sectors and the focus of the project will be on evaluation of service provision.

Evaluation skills are often overlooked in the majority of initial librarianship and museum training; they rarely feature significantly in courses. Perhaps as a result of this, in a series of surveys of public, academic, health, schools and special libraries in the British Isles carried out in 2003, a lack of staff skills was identified as a potential barrier to research in more than $40 \%$ of public, school and health libraries and just under one-third of academic libraries. This was linked to the issue of lack of time, which was the main barrier to greater involvement in research in all sectors; it was extremely timeconsuming for staff without adequate training or knowledge of suitable techniques to become involved in research (McNicol et al, 2003). These findings were supported by a survey carried out as part of the evalued project which found that evaluation in academic libraries was mainly carried out in-house by LIS staff. Just four institutions who responded to the survey had a designated evaluation officers. A lack of staff evaluation skills was mentioned by 13 respondents. 88\% (99 institutions) said they would welcome training opportunities in the evaluation of EIS (Thebridge et al, 2002).

As Powell, Baker and Mika (2002) have stated, involvement in research (which includes evaluation) can contribute to career advancement; improve an individual's ability to think critically and analytically; increase the effectiveness of decision-making and improve morale. The importance of research and evidence-based practice for the library profession has been acknowledged by CILIP in 
the Mapping the Research Landscape report (McNicol and Nankivell, 2003). Increasingly, external requirements for service accountability require staff to possess transferable evaluation skills and an understanding of the evaluation process.

Evaluation and evidence-based practice are of great importance for the sector as a whole. The concept of evidence-based policy has gained currency over the last decade. The 1999 White Paper, Modernising Government, clearly set out the government's philosophy on this issue (Cabinet Office, 1999). Evidence is a key concern of the Council for Museums, Archives and Libraries. It describes evidence as "the bedrock upon which decisions, policies and actions are based" (IMA, 2003). Staff awareness of, and involvement in, evaluation is vital to assist organisations in managing and planning services, based on robust data to inform decisions. However, many museum, archive and library staff lack the skills and confidence required to support these developments. A review of recent MLA programmes and consultation with the sector identified 'evaluation of services and evidence of impact' as a skills gap nationally within the sector (MLA, 2005).

\section{Methodology}

The partners in this project include museums, academic libraries and their archives, public libraries and their archives and health libraries. The first stage of the project, carried out by evidence base at the University of Central England (UCE), was to carry out an investigation of needs in terms of staff skills, focusing on evaluation, within the sector. The findings of this investigation will be used to inform the development of an approach to training which will be delivered in early 2006 . A number of individuals were interviewed in a selection of the project partner organisations to interview: a training officer or equivalent; a representative of the senior management team; one or more middle managers; and a number of front line staff. The precise questions asked varied slightly from group to group and depending on the types and scale of organisation and issues raised by the interviewees. The main themes covered were:

- Current evaluation activities and the role of individuals in these activities

- Difficulties or limitations of current evaluation activities

- Awareness and implementation of evidencebased practice within the organisation

- Current training opportunities offered in the broad evaluation area

- Overall opinions of current training opportunities (eg scope, effectiveness)

- Perceived skills gaps in the sector.

In addition, a short questionnaire was sent to each of the partner organisations asking them to provide basic information which will be used to inform the development of the training packages. The number of responses received from different types of organisation is detailed in the table below.

\begin{tabular}{|l|l|l|l|l|l|}
\hline $\begin{array}{l}\text { Type of } \\
\text { organisation }\end{array}$ & $\begin{array}{l}\text { Number of } \\
\text { organisations } \\
\text { visited (total } \\
\text { partner } \\
\text { organisations of } \\
\text { this type) }\end{array}$ & $\begin{array}{l}\text { Number of } \\
\text { senior managers } \\
\text { interviewed }\end{array}$ & $\begin{array}{l}\text { Number of } \\
\text { middle managers } \\
\text { interviewed }\end{array}$ & $\begin{array}{l}\text { Number of } \\
\text { front line staff } \\
\text { interviewed }\end{array}$ & $\begin{array}{l}\text { Number of } \\
\text { questionnaire } \\
\text { responses } \\
\text { received }\end{array}$ \\
\hline $\begin{array}{l}\text { Academic } \\
\text { library }\end{array}$ & $2(4)$ & 2 & 3 & 6 & 1 \\
\hline Public library & $2(2)$ & 2 & 3 & 9 & 2 \\
\hline Health library & $3(3)$ & 3 & 4 & 4 & 2 \\
\hline Archive & $1(4)$ & 0 & 2 & 0 & 0 \\
\hline Museum & $1(4)$ & 1 & 1 & 1 & 3 \\
\hline TOTAL & $\mathbf{9}(\mathbf{1 3})$ & $\mathbf{8}$ & $\mathbf{1 3}$ & $\mathbf{2 0}$ & $\mathbf{8}$ \\
\hline
\end{tabular}

Table 1: Organisations participating in the research 


\section{Evidence-based practice}

The term evidence-based practice was one which was more commonly used by managers than by front line staff. However, some senior and middle managers appeared to think of evidence only in terms of statistics. There is some indication that it may also be a term that is more commonly used in libraries than in other cultural organisations, but this hypothesis is based on a very limited sample.

Interestingly, it was a group of front line staff who gave the most rounded response to this question. Although they initially talked about the use of statistics rather than relying on impressionistic indicators, they went on to discuss the use of 'soft indicators'; the use of evidence in changing practice; and the importance of reflecting on and learning from past experiences. In other interviews, the use of external research and data from other institutions, for example, through benchmarking activities, was also mentioned.

It was ironic that the senior manager least familiar with the term evidence-based practice was the only one to directly mention staff feedback as a form of evaluation. In some larger organisations in particular, there seemed to be little interest in making use of the knowledge and skills or front line staff to improve services. Front line staff in these organisations were, in fact, keen to contribute to service improvement and often made small changes informally based on evidence collected by observing and talking to users. However, they felt that they had to keep these changes quiet; they believed that senior managers would not approve of any deviation from standard procedures, even if it was for the benefit of users. In smaller organisations, there were fewer of these hierarchical barriers and it appeared easier for all staff to contribute to service improvement.

In the health sector, evidence-based practice was often seen from a medical, rather than a library, perspective. This is, perhaps, not surprising given that the term originated in this field. Staff referred to carrying out literature searches which would help clinicians make informed decisions as an example of evidence-based practice. However, despite the fact that they may not automatically think of evidence-based practice as a way for the library itself used evidence to improve services, the staff interviewed in health libraries were aware of the importance of using evaluation and other data to improve services.

\section{Current evaluation activities}

A wide variety of evaluation activities is carried out in the project partner organisations including:

- Manually collected statistics e.g. gate counts, headcounts, PC bookings, visitor sign in

- Electronically collected statistics e.g. LMS (library management system) data

- Logs of reference enquiries

- Complaints and comments forms

- User surveys e.g. CIPFA, county-wide visitor survey, PSQG survey

- External surveys e.g. student satisfaction surveys, MORI polls, module evaluation forms, mystery shopper exercises

- Evaluation forms for specific events or promotions e.g. information skills sessions, events

- Workflow measures e.g. time taken for documentation delivery, time taken for book to get back onto shelves

- Stock audits

- Focus groups/library friends/library user groups/youth forum

- Consultation with staff, elected members and other partners

- Non-user surveys at community events

- Benchmarking data

- Collecting anecdotal examples of service impact e.g. letters, comments.

The purpose behind many activities was to provide data required as part of national schemes. Some of these were compulsory e.g. the public library service standards and new public library impact measures and HELICON (the NHS accreditation scheme). Others were not compulsory, but were national schemes in which the majority of organisations in the sector participated, e.g. CIPFA Library User surveys, 
PSQG Survey of Visitors to British Archives, SCONUL statistics. Being standard exercises, these have the advantage of allowing organisations to take part in benchmarking activities. A number of organisations were involved in other national schemes such as Investors in People or Chartermark which, although they were not so directly concerned with evaluation, did affect organisations' choice of data to collect. There was also mention of local or regional evaluation activities, such as a county-wide visitor survey.

However, it was worrying that a considerable amount of current evaluation seemed to be taking place with no specific purpose in mind. Some comments reflecting this problem included:

Librarians have always collected statistics and sometimes I think they should be acting upon them because what's the point in doing that unless they're for a purpose.

I think there are too many statistics collected around here!

There's a lot of data being collected, but how it's translated into anything meaningful is a question.

Another interviewee admitted that, while her organisation collected a lot of data, very little was actually analysed or used to improve services.

Perhaps part of the reason for this lack of focus is, as one interviewee put it, "Historically, librarians have thought, 'the library's always going to be here, so we don't really need to prove our worth'. But these days we do". On a similar note, another interviewee reflected that, in the past libraries often had their own ideas about what they thought was 'right' for local people and did this, but now people expect their views to have more influence and libraries needed to move towards that and away from the view that as professionals librarians automatically understand the issues. There were few examples of obviously purpose-led evaluation, but two of the health libraries mentioned the need to involve non-users in evaluation activities in order to find out how services might be promoted more effectively.

There was little theoretical discussion about the purpose of evaluation among interviewees.

However, one of the front line staff interviewed raised an interesting question: "The question is, do you evaluate what you think's important or what your customers think is important? It has to be what your customers think is important...we all know what we think is important, but that's not necessarily...[what customers think]". If the focus of evaluation activities was on areas which the library itself thought was most important, there was a danger that users might be experiencing problems which were not been investigated.

\section{The difficulties or limitations of current evaluation activities}

Even when there was a defined purpose for an activity, the evaluation which had been carried out was not always appropriate. For instance, one interviewee referred to an investigation into document delivery performance which she thought was not particularly meaningful as many of the factors affecting delivery times such as British Library response times were beyond the control of the library service. Similarly, another interviewee commented on the inadequacy of a shelving tracking survey intended to investigate the time taken for a returned book to get back onto the shelf:

If it takes thirty minutes for a particular book to be reshelved, we have no idea why. Was the counter really busy? Or were there a lot of shelvers off? I wonder if the data we've collected will ultimately be useful.

Another problem highlighted by some interviewees, particularly those with previous experience in the commercial sector, was the difficulty in evaluating a service where the main concerns were user, rather than cost, focussed and this was difficult to 'measure'. A few interviewees, especially at front line or middle management level, were concerned with a focus on inputs, outputs and processes, rather than outcomes and impacts in current library evaluation. Describing this issue in a university library scenario, one questioned: 
You can measure how many people come into the library etc, but what does that actually mean? Does the library make grades better? Or retention better?

However, he acknowledged the difficulty of providing evidence which would answer these types of questions, mainly because it was impossible to disaggregate the input which the library had from a myriad of other factors which might affect grades or retention. Certainly, the measures which were currently collected in his library were "perhaps ultimately not that useful" in even beginning to investigate these issues.

A lack of persistence was identified by one interviewee as a problem in library evaluation activities she had been involved in: "If the library runs sessions and no one comes, they don't run them again rather than finding out why no one came". She felt this was a mistake as "it's part of our job to reach people" and more time and effort needed to be put into this rather than giving up.

Several interviewees commented that the use of evidence to improve services could be hampered by the fact that information was often not shared effectively within the organisation. Another problem was that a lack of resources might mean it was not possible to act on many of the suggestions made by users as part of an evaluation and this could lead to frustration and a reluctance to participate in future evaluation activities.

\section{Staff involvement in evaluation activities}

Front line staff were primarily involved in activities such as handing out surveys to users and encouraging them to fill these in and collecting statistics. As the public face of the service, responding to comments was another activity front line staff were regularly involved in. In some cases, they also designed surveys or performed simple analysis, such as producing graphs of enquiry numbers for managers. It was more usual, however, for any data collected to be handed from front line staff to mangers in its raw form. Although some front line staff might have more of a say in local level surveys, many staff did not see evaluation as a key part of their role, which was focussed on delivery, but they did appreciate that they had a part to play in the overall process. The types of staff who were expected to participate even in these basic aspects of evaluation varied from organisation to organisation. For example, one interviewee commented that he would not normally expect someone employed as a receptionist to be involved in data collection activities such as handing out questionnaires, while in other organisations this was commonplace.

According to interviewees, senior managers were seen as taking a lead role in evaluation activities, setting the agenda and communicating this to other staff to ensure that everyone was aware of the importance of evaluation. However, it was clear that information about evaluation activities was not always communicated effectively. For instance, while it may sometimes be the case that the purpose of an evaluation activity was known to senior managers, this was not always communicated to other staff; they were not aware why they were being asked to do particular evaluation tasks. The amount of feedback to front line staff about evaluation findings also varied. Although most organisations claimed to do this through staff briefings or newsletters, some front line staff felt they were only given very superficial information and would like more detail about the findings. For example, one felt that "Data from surveys disappears into a black hole of files somewhere without any discussion among us [front line staff] about the results".

The appraisal process was seen as a way to communicate organisational plans and goals to staff and to help them to see how their role contributed to higher level aims. However, while staff were aware that this was theoretical aim of the process, they were not clear about how this translated into practice:

Whether someone sits down and thinks about what we do and how it drives those [higher level objectives]... if it does happen, it happens a long way above my head.

Any outcomes which were identifiable to front line staff in their day-to-day work were "very library focussed" rather than reflecting organisational goals. 
Senior managers thought that it was often difficult to engage other staff in evaluation activities. However, the vast majority of front line staff interviewed were well-aware of the importance of evaluation and they suggested ways in which it might be improved. Despite the reservations expressed by managers about the value front line staff placed on evaluation, those interviewed felt that it was a valuable activity because it could help the organisation to find ways to improve. They saw that statistics and other data showed how well the organisation was performing and whether new initiatives had an impact, by increasing issues for example. Front line staff were also aware of the need to 'look behind' the numbers and to find out why certain statistics had increased or decreased for instance and also to ensure that statistics were supported by contextual information. As one said, "Data without context is just a number; you can collect all the numbers you want...". The sheer volume of evaluation activity, particularly, statistics was identified as a problem for front line staff:

There's just so much bureaucracy...it's just so demotivating. The problem is that evaluating and collecting evidence is supposed to motivate you because it will, hopefully, show that you're doing something constructive, but instead you start complaining about it...it's having a negative effect rather than anything positive.

The phrase, 'show you're doing something'. A lot of the time that can feel like what you're doing...we're justifying our existence...but ultimately we're not!

From the limited number of organisations visited as part of this research, it would seem that in smaller organisations there was less division between the roles of staff at different levels, and staff at lower levels were able to take greater initiative with regard to evaluation activities than might have been the case in a larger, more complex organisation.

\section{The use of evaluation data}

Three main uses of evaluation findings were mentioned in interviews: reporting; service development; and, interestingly, staff morale.
It was common for evaluation findings to be discussed by committees at various levels, both within the library and within the wider organisation. In most organisations, front line staff were informed of at least some of the findings of evaluation activities. In some cases, evaluation activities were communicated more widely. Only one organisation referred to the importance of feeding back findings to users.

Despite the fact that a substantial proportion of current evaluation appeared to be being undertaken without a clear purpose in mind, there were a number of examples given to demonstrate how evidence had been used to improve services. Some examples are described below.

- In a health library which had evaluated the impact of literature searches on clinical practice, the results had indicated the value of a mediated service. As well as confirming the value of the service offered by this library, sharing this information had helped other libraries to see the value of a mediated service and to consider offering this type of service.

- Evaluating a pilot clinical librarian project had enabled a health library to make the case for this post to be funded for a further two years. This was the only instance of a specific evaluation activity being directly linked to securing funding.

- In one library, data obtained via the library management system had been used to review the loans policy. The data showed that this library had more renewals than comparable libraries in other institutions and this was increasing staff workloads, so it was decided to extend loan periods.

- A public library had changed its opening hours as a result of a survey of users and nonusers.

- An archive service had made a number of minor, low cost improvements in response to visitor comments, for example, moving the fiche printer in the public area so it could be a self-service facility; allowing open access to microfilm materials; and having coloured receiving spools on microfilm readers. 
- Where they had more freedom to act on their own initiative, some front line staff had used evaluation findings to make small improvements to practice. For example, in one library, an analysis of enquiries had been used to compile a FAQs folder which users could be referred to.

Front line staff in particular appreciated that evaluation could be a positive experience for staff as it could demonstrate how things were improving and provide positive feedback from customers as well as highlighting problems. They could be demoralising, however, if there was no apparent point to them from the perspective of front line staff.

\section{Current evaluation and evidence-based training provision}

Overall, very little training in evaluation was reported. Any training which has taken place tended to be informal, for example one member of staff who had developed skills in a particular area passing on their knowledge to others on an informal basis. An academic library was more fortunate as it had access to courses on research skills primarily intended for academic staff. Some public library staff had received training in race equality impact measurement. A member of staff from a health library had been on a business planning course and two further staff had attended a course called Value Your Service which involved carrying out a practical exercise to evaluate the impact of library services on clinical practice.

Although there were few opportunities specifically in evaluation, many training opportunities did exist in the broad area of communication skills which might prove valuable for activities such as running focus groups or interviewing. Examples included: staff appraisal training; interviewing skills; supervisory skills; adult guidance; reference enquiry; customer care; presentation skills; team building; coaching/mentoring; and cultural awareness. In addition, some training opportunities were offered, primarily to staff at management level, in project management.
Despite the lack of existing opportunities, only a few interviewees commented on particular areas of evaluation where they felt existing skills were particularly weak. The two main aspects mentioned were data analysis and running focus groups. Several staff felt they, or others in their organisation, did not have the skills, especially the statistical skills, required to analyse data and needed to develop better interpersonal and communication skills to feel more comfortable running focus groups. More complex types of evaluation, such as measuring the impact of the library services in various contexts, was an area in which a few interviewees felt that staff skills were currently weak. Appropriate ways of feeding findings back to users was another area mentioned as was methods of surveying nonusers. It is also worth noting that as well as skills, many staff simply wanted training which would provide them with greater confidence in evaluation activities.

\section{The problems of implementing training}

Even when training was available, implementing it in the workplace was felt to be difficult. One of the main difficulties was the need to enthuse and involve, or simply secure support from, other staff. One interviewee reflected on the difficulties she had experienced:

The problem is that you come back from a course enthused and try out new ideas on other people and it grinds you down when people aren't as enthusiastic because they have done something the same way for years and years...they refuse to change because 'we're librarians and we know better'...

There was little recognition at a senior level that staff may need support from the organisation in implementing training. One training officer interviewed felt:

It's down to the individual; they've got to come back... and they've got to try and implement it...they shouldn't be going on the training if it's not relevant to them, they won't be using it.

Another difficulty for some staff was that they were not allowed sufficient freedom within their organisation to be able to introduce new ideas they had gained through training. In some larger organisations, front line staff in particular 
felt constrained by the very rigid rules and procedures they were expected to follow; they felt that creative thinking was frowned on rather than encouraged.

Many existing courses are generic, and not tailored to the specific needs of libraries, museums or archives; this can make it difficult for staff to see the direct relevance of these to their day-to-day work and some experienced difficulties understanding how to put skills and knowledge they have gained from a training programme into practice. The format of the training might also affect how easily staff could put it into practice. Staff in a number of organisations commented that they preferred training to include practical as well as theoretical elements which allowed them to experience how they might put techniques into practice.

Money was another barrier to implementing training, for smaller organisations in particular. This meant that, as one interviewee said, "Perhaps only $10 \%$ is put into practice usually because there's not the money to do so, but even that $10 \%$... sometimes it can give you the kick you need". Time was, of course, another consideration which affected how effectively training could be implemented in practice.

\section{Conclusion}

The value of developing training in evaluation and evidence-based practice was summed up by one interviewee, who reflected:

Management skills and librarian-type skills obviously aren't the same and although we might be excellent librarians, you have to grow into being a good manager and this is part of being a good manager.

It must be remembered that the findings of this project are based on a small sample of project partners who have expressed an interest in the area of evaluation and evidence based practice. However, they suggest that museums, archives and libraries need to streamline existing data collection exercises, for example, by paying more attention to the following:
- making better use of existing data, both that collected by the organisation and that collected externally

- only collecting further data when it is intended to be used for a specified purpose

- reducing the number of statistics collected where possible

- considering the different types of evidence which might be used as part of evidence based practice e.g. tacit knowledge, informal feedback

- not collecting data which is not being used.

The organisation of evaluation activities appears to be an area where there is considerable scope for improvement. The use of front line staff is particularly poor; their strengths need to be harnessed much more effectively. Front line staff need to be allowed to take more initiative than is currently permitted, especially in larger organisations. Most front line staff interviewed for this research certainly had a higher level of knowledge and awareness than they were given credit for by senior managers. A number are currently attempting to use evaluation to improve services despite of senior managers. It is rarely appreciated that staff at all levels need to be involved in the analysis and use of evaluation data as well as its collection. The potential benefits of evaluation for improving staff morale are rarely appreciated at a senior level and this is a missed opportunity. Linked to this, there is a need to improve communication about evaluation activities within organisations, in particular between senior managers and front line staff. The findings of evaluation exercises need to be reported more effectively to ensure that all stakeholders (including front line staff and users) are informed of the findings and actions to be taken as a result.

However, perhaps the most important issue emerging from this research is the need for stronger links between evaluation and service development within the sector. There are numerous examples of data collection activities which have no purpose and at the same time, there seems to be a lack of awareness of the range of potential uses of evaluation, for example, promotion or securing funding. 


\section{The next stage}

The next stage of this project is to develop a training programme for senior managers, middle managers and front line staff to help them to see how they might implement techniques in their own working environment. The training will take an organisational, rather than an individual, approach, that is, training a number of people in a single organisation so they can support each other in implementing the training and have the support of senior managers. Staff at all levels will have the opportunity to become actively involved in the evaluation of their own service. The training will highlight the benefits of evaluation, build staff confidence and facilitate opportunities for networking and understanding of areas of commonality with other organisations.

Of course a project such as this cannot solve all the problems identified in the initial research reported above. However, it is hoped that the training developed will help to change attitudes towards evaluation and evidence-based practice and allow organisations to take a more considered and coherent approach to service improvement.

\section{References}

Cabinet Office (1999), Modernising Government, London: HMSO.

DCMS (200I), Comprehensive, Efficient and Modern

Public Libraries - Standards and Assessment, London: DCMS.

Demos (2003), Towards a Strategy for Workforce

Development, London: Resource.

IMA (2003), Evidence-based Museums, Archives and Libraries Work: Discussion Document, London: Resource.

McNicol, S. Kane, D., Lancaster, K. and Spry, J. (2003)

Research in libraries: a cross-sectoral comparison, [available at

http://www.cie.uce.ac.uk/cirt/practitioner_surveys.htm].

McNicol, S. and Nankivell, C., (2003), The LIS Research Landscape:A Review and Prognosis [available at http://www.cie.uce.ac.uk/cirt/projects/past/LISlandscape _final\%20report.pdf].

MLA (2005) Developing Skills Sets To Deliver Modern Museum, Library Services: Invitation to Tender. http://www.mla.gov.uk/documents/0079brf.doc

Powell, Ronald R, Baker, Lynda M, and Mika, Joseph J (2002), "Library and Information Science Practitioners and Research", Library and Information Science Research 24, pp. 49-72.

Resource (200I), Museum learning online: guidelines for good practice, London: Resource.

Society of Archivists (various dates), Best Practice Guidelines for Archives series, London: Society of Archivists.

Thebridge, S., Dalton, P., Bhatt, A., and Hartland-Fox, R. (2002), Questionnaire to Higher Education Institutions in the UK Analysis of responses [available at http://www.ebase.uce.ac.uk/evalued/Library/Paper I_ QuAnalysis.pdf]. 